\title{
Detection of drought tolerance-related QTL in the Plainsman V./ Cappelle Desprez doubled haploid wheat population
}

\author{
É. Nagy ${ }^{1,5} \cdot$ Á. Szabó-Hevér ${ }^{2} \cdot$ S. Lehoczki-Krsjak ${ }^{3} \cdot$ C. Lantos $^{1} \cdot$ E. Kiss $^{4} \cdot$ J. Pauk $^{1}$
}

Received: 18 September 2021 / Accepted: 22 November 2021 / Published online: 11 December 2021

(c) The Author(s) 2021

\begin{abstract}
Drought stress is one of the major abiotic factors that significantly reduces wheat grain yield. Improving drought tolerance is a challenge that plant breeders are facing nowadays. In this study, our goal was to identify quantitative trait loci (QTL) in the Plainsman V./Cappelle Desprez doubled haploid (DH) population under drought induced as decreased irrigation (ds) and well-watered (ww) conditions in glasshouse. In total, 54 QTL were detected across the three years in two water regimes linked to 10 drought tolerance-related agronomic traits. Out of the detected QTL regions several have been previously reported. The QTL on chromosome 1A (wPt-744613-wPt-8016) related to thousand grain weight was detected in both ds and ww conditions, explaining the $12.7-17.4 \%$ of the phenotypic variance. QTL for grain yield was detected on chromosomes $1 \mathrm{~A}$, and 6B in the ds treatment. Numerous QTL was identified under both irrigation levels.
\end{abstract}

Keywords Drought $\cdot$ Wheat $\cdot$ QTL $\cdot$ Grain yield

\section{Introduction}

Wheat is one of the most widely grown cereal species all over the world (El-Feki et al. 2018). Nowadays, the climate change has strong influence on the productivity of wheat. Adequate soil moisture is essential for proper growth and development of crop species, which ultimately leads to optimum productivity (Kadam et al. 2012). Drought stress is the major abiotic factor that reduces wheat grain yield (Dashti et al. 2007; Safar-Noori et al. 2018).

Drought tolerance is a complex quantitative character comprising of several physio and biochemical processes at the cellular and molecular level at different stages of the plant development (Kadam et al. 2012). Drought tolerance

\section{J. Pauk}

janos.pauk@gabonakutato.hu

1 Cereal Research Non-Profit Ltd, Szeged, Hungary

2 Edward T. Schafer Agricultural Research Center, USDA-ARS, Fargo, ND, USA

3 Faculty of Science and Engineering, Southern Cross University, Lismore, NSW, Australia

4 Hungarian University of Agriculture and Life Sciences, Gödöllő, Hungary

5 Oud's Amazone Trading PTY LTD, Federal, NSW, Australia is controlled by multiple genes, with each gene having a relatively small effect (Zhang et al. 2013). Most of the droughtrelated traits are also quantitative (Teulat et al. 2003). Plants adapt to drought stress in many ways, including enhanced water uptake by developing large root system, reduced water loss by increasing stomatal resistance, and adaptation to water shortage by accumulation of cellular osmolytes (Rampino et al. 2006; Tavakol et al. 2016).

Breeding varieties with improved drought tolerance is one of the most important goals for plant breeders. This could be enhanced by the understanding the genetic and molecular bases of drought tolerance (Zhang et al. 2011; Sinha et al. 2018). Genomics-assisted improvement of abiotic stress tolerance of crops is relying on the QTL approach (Collins et al. 2008). The QTL analysis based on high-density molecular linkage maps has become a useful tool to understand the genetic background of drought tolerance. Diversity Array Technology (DArT, Kilian et al. 2012) has been used in previous QTL studies of wheat, providing high-density genotypic map by detecting large number of DNA variants (El-Feki et al. 2018). In wheat, drought stress QTL mapping has been applied at different plant developmental stages and was carried out at several morpho-physiological traits in different mapping populations. Most of the reported QTLs for drought tolerance in wheat were identified for yield or yield components under limited water conditions (Nasseer et al. 
2016). Grain yield is highly affected by environmental factors (Gao et al. 2015). Also, a complex trait, regulated by factors, which are not equally effective (Wang et al. 2016). Therefore, the understanding and identification of QTLs or genes that influence yield can help breeders with the genetic improvement of high yielding varieties (Guan et al. 2018). Grain yield in wheat can usually be described by yield components, the spikes per plant, the grain number per spike, and the thousand kernel weight, and the plant number per given area. The yield component traits are also influenced by several physiological traits like plant height $(\mathrm{PH})$ and biomass (BM) in different populations (Guan et al. 2018; Pouri et al. 2019). Furthermore, $\mathrm{PH}$ could be a suitable trait to model the dissection of drought tolerance (Zhang et al. 2011). Flowering time is another important trait in drought tolerance (Bennet et al. 2012b). Root systems are crucial to plants for adaptation to suboptimal conditions (Liu et al 2013). Underwater stress conditions, plants often develop deep and extensive root systems as an adaptive strategy ( $\mathrm{Li}$ et al 2014.). Extensive root systems were positively associated with higher grain yield in the case of rice under drought stress (Lafitte et al. 2004).

More than 500 QTLs related to grain yield and its components have been previously reported on all chromosomes in the wheat genome under drought stress conditions (Zhang et al. 2010). Bennet et al. (2012b) reported grain yield (GY)related QTLs on 1A, 1B, 2A, 2B, 2D, 3A, 4D, 6D, 7A chromosomes. In addition, Kadam et al. (2012) detected QTL regions on $2 \mathrm{D}, 3 \mathrm{D}, 4 \mathrm{~B}, 5 \mathrm{~A}$ chromosomes which were associated with GY. Mathews et al. (2008) reported QTLs related to $\mathrm{GY}$ on $1 \mathrm{~A}, 1 \mathrm{~B}, 2 \mathrm{~A}, 2 \mathrm{~B}, 3 \mathrm{~A}, 3 \mathrm{~B}, 4 \mathrm{~A}, 4 \mathrm{~B}, 5 \mathrm{~A}, 6 \mathrm{~B}, 7 \mathrm{~A}, 7 \mathrm{~B}$ chromosomes of wheat. Detected regions can be used in breeding and pre-breeding to increase its efficiency through marker-assisted selection (Pinto et al. 2010; Gao et al. 2016). In addition, phenotyping plays a crucial role in gene discovery and in understanding the complex interactions between genes, genetic background, and environment (Lopes et al. 2013). The goal of the present study was to identify QTL regions in the Plainsman V. (Pl)/Cappelle Desprez (CD) DH population under drought stress and optimal irrigation conditions in glasshouse experiments.

\section{Materials and methods}

\section{Plant material}

The winter wheat DH population, used in this study, consisted of $135 \mathrm{DH}$ lines derived from a cross between the drought-tolerant Plainsman V. (Pl) and the drought-sensitive Cappelle Desprez (CD) varieties (Gallé et al. 2009). The DH population was developed from the anther culture of the F1 generation followed the protocol of Pauk et al. (2003).
Pl (year of release, 1974) is an American hard red winter wheat with high protein content and has excellent drought tolerance. CD (year of release, 1946) producing high yield in intensive farming conditions, but sensitive to drought, was bred in France (Gallé et al. 2009).

\section{Glasshouse experiments}

The experiments were carried out in 2014, 2015, 2016, under glasshouse conditions in Szeged. The one-week-old seedlings were vernalized at $4{ }^{\circ} \mathrm{C}$ in a cold chamber, under continuous dim light for 6 weeks. The seedlings of DH lines were planted in February. The pots contained soil mixture (526 g peat soil, and $1340 \mathrm{~g}$ dry sandy soil) and $4 \mathrm{~g}$ controlled release fertilizer (Osmocote Exact, Scotts Company, Marysville, Ohio, including $\mathrm{N} 16+\mathrm{P} 9+\mathrm{K} 12+2,5 \mathrm{MgO}$ ). Each DH line was planted in two pots/treatment and two (2014) or three $(2015,2016)$ plants/pot. The experiment was carried out from the end of February till mid-June, in controlled conditions using the standard glasshouse wheat growing program. Prior to the experiment, the water capacity of the used soil mixture was determined (Cseri et al. 2013). At the time of potting, the wheat plants were watered with $100 \mathrm{ml}$ water/pot to ensure the adaptation of seedling.

Pots were irrigated twice weekly. The well-watered (ww) plants were irrigated to the $60 \%$ of the soil water capacity. Five ww Pl and five CD pots weight was measured by a computer-controlled balance (GSE model 350, 6.000 $\pm 1 \mathrm{~g}$ ), which gave the average irrigation norm. In the ww treatment each plant during the experiment got $1575 \mathrm{ml}$ water in 2014 (the 2015 experiment has been previously reported Nagy et al. 2017), and $1025 \mathrm{ml}$ water in 2016. In the drought stress (ds) treatment, the plants were irrigated to the $20 \%$ of the soil water capacity in the same way as in the ww treatment. During the growing season the stressed plants got $575 \mathrm{ml}$ in 2014, $475 \mathrm{ml}$ water in 2016.

\section{Recorded traits}

The days from sowing to heading (HT heading time) were registered individually for each plant when the spike left the leaf sheet completely. The plant height was measured from the ground to the top of the spike. The whole plants were harvested and dried in drying cabinet at $40{ }^{\circ} \mathrm{C}$ to the constant weight and the aboveground biomass (BM), spike length (SL), non-threshed spike weight (SW), number of grains/ mean ear (GNE), and total grain yield/plant (GY), thousand grain weight (TGW) were measured.

At the end of the experiment root dry mass was measured in 2015. Harvest index (HI) was calculated as the ratio between harvestable yield and aboveground biomass, as reported by Donald (1962), and Passioura (1983). 
Broad sense heritability $\left(\mathrm{h}^{2}\right)$ was calculated with the following formula: $\mathrm{h}^{2}=\mathrm{o}_{\mathrm{g}}{ }^{2} /\left(\mathrm{o}_{\mathrm{g}}{ }^{2}+\mathrm{o}_{\mathrm{ge}}{ }^{2} / \mathrm{n}+\mathrm{o}^{2} / \mathrm{nr}\right)$ where $\mathrm{o}_{\mathrm{g}}{ }^{2}$ is the genotypic effect, $o_{\mathrm{ge}}{ }^{2}$ is the genotype by environment effect, $\sigma^{2}$ is the residual error, $\mathrm{n}$ is the number of genotypes and $r$ is the number of errors (Guan et al. 2018).

\section{Statistical analysis}

The normality of data was checked with Kolmogorov-Smirnov test by IBM SPSS statistics 22 software. Analyses of the collected data were made by IBM SPSS Statistics 22 software 'Descriptive statistics' function to calculate means, minimum and maximum values, percentiles, standard deviation (heading time, plant height, grain yield, aboveground biomass, non-threshed spike weight and root dry mass).

The 'General Linear Model' (GLM) function was used to perform the two-way ANOVA, investigating the genotypeby-treatment interactions. Correlation analysis was performed for each treatment separately (ww, ds) on the population average of the three years using IBM SPSS Statistics 22 software 'Pearson Correlation' function.

\section{DNA isolation and molecular markers}

DNA was isolated from seedling leaf tissue according to the CTAB method (Rogers and Bendich 1985). The quality and quantity of DNA were measured with a NanoDrop 1000 Spectrophotometer (Thermo Scientific, USA).

To map the Pl/CD population, a database of 897 DArT markers was used. The DArT marker data were provided by the Australian Diversity Arrays Technology Pty Ltd (Lv. D, Bldg. 3, University of Canberra, Bruce ACT 2617, Australia).

\section{Molecular mapping and QTL analysis}

Linkage groups were constructed by using JoinMap® 3.0 software (Van Ooijen and Voorrips 2001), and interval mapping was carried out with MapQTL ${ }^{\circledR} 5$ software (Van Ooijen 2004). Interval mapping (IM) was carried out with the average of each trait. The permutation tests (determined by 1000 iterations) indicated minimum LOD scores between 1.5 and 2.1 at $\mathrm{P}=0.05$ significance level (Van Ooijen 1999).

\section{Results}

In the experiments, $135 \mathrm{DH}$ lines of the Plainsman V./Cappelle Desprez population were tested in glasshouse under ds and ww conditions for three years. Yield-related agronomic traits, plant height and root dry mass were measured; HI was calculated.

\section{Phenotypic results}

The two parental varieties and $135 \mathrm{DH}$ lines were grown in pots for the phenotyping of drought-responsive traits for three years. In the experiments, all traits showed lower values under stress condition than under ww condition (S1.). The phenotype results of the 2015-year experiment have been reported earlier (Nagy et al. 2017). Within the experiments significant variation between the tested $\mathrm{DH}$ lines was measured. Pl had less GY under ww conditions compared to $\mathrm{CD}$. On the other hand, under ds conditions Pl had less yield depression compared to $\mathrm{CD}$. In the experiments 2014, 2016 the highest $\mathrm{h}^{2}$ value was found for HT and $\mathrm{PH}$, the lowest value was for GY (S1.)

Significant correlations were found between traits (data not shown). The PH, HT, BM traits were positively correlated with each other under both conditions. GY under ww conditions positively correlated with BM $(r=0.573)$, SW $(r=0.439)$, GNE $(0.360)$ at the 0.01 probability level.

A different result was observed under ds conditions, namely GY positively correlated with $\mathrm{PH}(\mathrm{r}=0.175)$ at the 0.05 probability level. Furthermore, negative correlation was observed between GY and HT $(r=-0.185)$ at the 0.05 probability level. Also, positive correlation was found between GY and BM $(r=0.428)$, SW $(r=0.758)$, GNE $(r=0.540)$ under ds conditions at the 0.01 probability level.

\section{Marker analysis and map construction}

The total marker dataset included 897 DArT markers. The created 36 linkage group consisted of 810 DArT markers and represented the 21 chromosomes covering a genetic distance of $1317 \mathrm{cM}$. The $\mathrm{D}$ genome had the lowest map distance and number of markers. For chromosome 1D- 11, 4D- 2, 5D- 2, and $6 \mathrm{D}-5$ markers were mapped. The average map length was $62.5 \mathrm{cM} /$ chromosome.

\section{QTL analysis}

In total 54 QTL regions were detected across the three years and two water regimes with 10 traits in the $\mathrm{Pl} / \mathrm{CD}$ DH population (Table 1). The QTL distribution was balanced between the two water regimes. In total 22 QTL were detected under ds conditions; another 19 QTLs were found in the ww treatment. Furthermore, 13 QTL were detected under both conditions. In addition, 2 QTL were detected in all years and water regimes associated with $\mathrm{PH}$ on chromosome 4B, 6B. The QTL frequency was the highest on the B genome (55.5\%), on the A genome 23 QTL were detected (42.5\%). Only 1 QTL was identified on the D genome (1.8\%). The highest 
Table 1 The detected QTLs for agronomic traits of the Plainsman V/Cappelle Desprez DH population under two water regimes (ww; ds) for three years $(2014-14 ; 2015-15 ; 2016-16)$ in glasshouse

\begin{tabular}{|c|c|c|c|c|c|c|c|}
\hline Trait & Environment & CHR & Marker interval & $\mathrm{cM}$ & LOD & A & $\mathrm{R}^{2}$ \\
\hline \multirow[t]{7}{*}{ PH } & $15 w w, 16 w w$ & $1 \mathrm{~A}$ & wPt-5367-wPt-8016 & $51.6-57.3$ & 2.82 & -2.47 & 9.2 \\
\hline & $15 \mathrm{ds}$ & $2 \mathrm{~B}$ & wPt-7715-wPt-9978 & $51.83-54.48$ & 2.07 & -1.70 & 7.0 \\
\hline & $14 \mathrm{ww}, 14 \mathrm{ds}$ & $3 \mathrm{~B}$ & wPt-6043-tPt-6487 & $96.1-106.9$ & 3.30 & -2.48 & 9.9 \\
\hline & all & 4B & wPt-5334-wPt-5497 & $18.24-21.59$ & $2.6-11.37$ & -1.85 & $9.7-37.3$ \\
\hline & $14 \mathrm{ds}$ & $5 \mathrm{~B}$ & wPt-743712-wPt-9666 & $13.22-27.15$ & 2.84 & 1.85 & 9.2 \\
\hline & all & $6 \mathrm{~B}$ & wPt-663764-wPt-2175 & $40.21-47.04$ & $2.22-3.07$ & -2.39 & $7.3-17$ \\
\hline & $15 \mathrm{ds}, 16 \mathrm{ds}$ & $7 \mathrm{D}$ & wPt-665471-wPt-744346 & $8.42-13.98$ & 3.39 & 2.18 & 11.0 \\
\hline \multirow[t]{4}{*}{ HT } & $14 \mathrm{ww}, 16 \mathrm{ww}, 15 \mathrm{ds}, 16 \mathrm{ds}$ & $1 \mathrm{~B}$ & wPt-3950-wPt-1973 & $0.0-11.81$ & $2.56-3.18$ & -1.49 & $8.5-10.1$ \\
\hline & $15 \mathrm{ds}$ & $2 \mathrm{~B}$ & wPt-5250-wPt-744643 & $57.78-60.23$ & 2.40 & 1.27 & 7.9 \\
\hline & 14ww, 16ww & $3 \mathrm{~B}$ & wPt-6376-wPt-9514 & $110.9-115.1$ & 7.97 & -3.79 & 23.8 \\
\hline & $15 w w, 16 w w$ & $5 \mathrm{~B}$ & wPt-2707-wPt-0935 & $130.24-145.87$ & 2.48 & 1.24 & 8.2 \\
\hline \multirow[t]{2}{*}{ BM } & $14 w w, 15 w w$ & $3 \mathrm{~B}$ & wPt-6376-wPt-9514 & $113.4-115.1$ & 3.39 & -0.39 & 11.0 \\
\hline & $16 \mathrm{ds}$ & $6 \mathrm{~B}$ & wPt-4924-wPt-1307 & $99.54-111.03$ & 2.45 & -0.03 & 9.5 \\
\hline \multirow[t]{4}{*}{ SW } & $15 \mathrm{ds}$ & $1 \mathrm{~A}$ & wPt-664968-wPt-734301 & $96.52-99.17$ & 3.07 & 0.04 & 21.8 \\
\hline & $14 w w, 15 w w$ & 1B & wPt-3266-wPt-2597 & $134.3-145.0$ & 2.92 & 0.07 & 9.3 \\
\hline & $14 \mathrm{ww}, 16 \mathrm{ww}, 15 \mathrm{ds}, 16 \mathrm{ds}$ & $3 \mathrm{~B}$ & wPt-9826-wPt-741322 & $41.4-45.24$ & $2.08-4.07$ & -0.26 & $6.9-16.3$ \\
\hline & $16 w w$ & $5 \mathrm{~B}$ & tPt-8942-wPt-0963 & $38.09-53.71$ & 2.52 & -0.05 & 8.2 \\
\hline \multirow[t]{7}{*}{ SL } & $14 \mathrm{ww}, 14 \mathrm{ds}, 15 \mathrm{ww}, 16 \mathrm{ww}$ & $1 \mathrm{~A}$ & wPt-741357-wPt-6280 & $0.00-16.74$ & 3.97 & -0.39 & 12.7 \\
\hline & $14 \mathrm{ww}, 15 \mathrm{ww}, 14 \mathrm{ds}$ & $2 \mathrm{~A}$ & wPt-1722-wPt-731381 & $0.00-14.93$ & $2.66-2.97$ & -0.38 & $8.6-11.1$ \\
\hline & $14 \mathrm{ds}, 16 \mathrm{ds}$ & $2 \mathrm{~B}$ & wPt-6311- wPt-5759 & $58.91-68.53$ & 2.88 & 0.33 & 9.4 \\
\hline & $14 \mathrm{ww}, 16 \mathrm{ww}, 14 \mathrm{ds}$ & $3 B$ & wPt-11218-wPt-0212 & $76.66-82.62$ & 2.99 & 0.36 & 10.6 \\
\hline & $16 w w$ & $5 B$ & wPt-5092-wPt-1548 & $89.67-97.88$ & 2.62 & -0.31 & 8.5 \\
\hline & $15 w w, 16 w w$ & $6 \mathrm{~A}$ & wPt-666773-wPt-5654 & $105.97-117.11$ & $2.29-3.44$ & 0.34 & $7.5-11.0$ \\
\hline & $15 w w, 16 w w, 14 d s$ & $7 \mathrm{~A}$ & wPt-5949-wPt-3992 & $73.12-107.32$ & $3.64-3.67$ & 0.38 & 12.5 \\
\hline \multirow[t]{3}{*}{ GNE } & $15 w w$ & $2 \mathrm{~A}$ & wPt-1722-wPt-3896 & $0.0-14.2$ & 3.04 & -1.98 & 9.9 \\
\hline & $14 \mathrm{ww}, 16 \mathrm{ww}, 15 \mathrm{ds}$ & $3 \mathrm{~B}$ & wPt-6376-wPt-9514 & $113.43-115.08$ & $2.31-3.85$ & -4.18 & $7.8-12.7$ \\
\hline & $15 \mathrm{ww}, 16 \mathrm{ww}, 15 \mathrm{ds}$ & $6 \mathrm{~A}$ & wPt-666773-wPt-6696 & $105.97-118.24$ & $3.24-4.96$ & 3.04 & $10.5-15.7$ \\
\hline \multirow[t]{7}{*}{ GY } & $15 w w$ & $1 \mathrm{~A}$ & wPt-669499-wPt-0432 & $59.3-62.6$ & 2.82 & -0.06 & 12.8 \\
\hline & $15 \mathrm{ds}$ & $1 \mathrm{~A}$ & wPt-664666-wPt-734301 & $96.5-99.1$ & 3.45 & 0.04 & 24.0 \\
\hline & $14 w w$ & $3 \mathrm{~A}$ & tPt-0519-wPt-7271 & $20.9-27.2$ & 3.15 & -0.09 & 10.5 \\
\hline & $14 w w, 16 w w$ & $3 \mathrm{~B}$ & wPt-7486- wPt-11218 & $69.9-76.6$ & $2.46-2.71$ & 0.05 & $8.6-8.8$ \\
\hline & $14 w w$ & $5 B$ & wPt-1733-wPt-1304 & $105.88-142.75$ & 3.30 & -0.10 & 10.6 \\
\hline & $14 w w$ & $6 \mathrm{~B}$ & wPt-1307-wPt-664252 & $111.03-132.91$ & 2.40 & -0.10 & 12.1 \\
\hline & $15 \mathrm{ds}$ & $6 \mathrm{~B}$ & wPt-743215-wPt-6293 & $0.00-6.29$ & 2.56 & -0.02 & 9.1 \\
\hline \multirow[t]{4}{*}{ HI } & $15 w w$ & $1 \mathrm{~A}$ & wPt-744613-wPt-0432 & $40.5-62.6$ & 4.48 & -0.01 & 17.6 \\
\hline & $15 \mathrm{ds}$ & $1 \mathrm{~A}$ & wPt-665590-wPt-4801 & $122.88-130.17$ & 2.64 & 0.01 & 8.5 \\
\hline & $16 w w$ & $3 \mathrm{~B}$ & wPt-9443-wPt-11218 & $74.94-76.66$ & 3.01 & 0.01 & 9.7 \\
\hline & $14 w w$ & $6 \mathrm{~A}$ & wPt-0696-tPt-9048 & 107.97-109.52 & 3.06 & 0.01 & 9.9 \\
\hline \multirow[t]{9}{*}{ TGW } & $15 \mathrm{ds}, 16 \mathrm{ds}$ & $1 \mathrm{~A}$ & wPt-744613-wPt-8016 & $40.5-57.34$ & $3.36-4.66$ & -1.78 & $12.7-17.4$ \\
\hline & $15 \mathrm{ds}$ & $1 \mathrm{~B}$ & wPt-2575 & $185.10-191.02$ & 2.37 & 1.40 & 7.7 \\
\hline & $14 \mathrm{ds}, 15 \mathrm{ds}$ & $3 \mathrm{~A}$ & wPt-7608-wPt-2755 & 68.31469 .84 & 2.67 & -1.47 & 8.5 \\
\hline & $14 \mathrm{ds}, 15 \mathrm{ds}, 16 \mathrm{ds}$ & $4 \mathrm{~B}$ & wPt-1849-wPt-4243 & $0.0-41.09$ & $2.42-4.21$ & -2.03 & $8.6-16.5$ \\
\hline & $15 \mathrm{ds}, 16 \mathrm{ds}$ & $5 \mathrm{~B}$ & wPt-5896-wPt-1881 & $126.21-146.36$ & 3.08 & 1.67 & 10.1 \\
\hline & $15 \mathrm{ww}, 15 \mathrm{ds}, 16 \mathrm{ds}$ & $6 \mathrm{~A}$ & wPt-666773-wPt-6696 & $105.97-118.24$ & $2.24-3.94$ & -1.67 & $7.3-12.3$ \\
\hline & $15 \mathrm{ww}, 14 \mathrm{ds}, 15 \mathrm{ds}, 16 \mathrm{ds}$ & $6 \mathrm{~B}$ & wPt-743215-wPt-4564 & $0.00-23.24$ & $2.75-4.42$ & -1.39 & $9.0-13.9$ \\
\hline & $14 w w$ & $7 \mathrm{~A}$ & wPt-8377-wPt-6083 & $87.57-103.84$ & 2.89 & -1.39 & 7.9 \\
\hline & $16 \mathrm{ds}$ & $7 \mathrm{~A}$ & wPt-741971-wPt-7267 & $36.99-38.79$ & 2.33 & -1.22 & 10.1 \\
\hline \multirow[t]{2}{*}{ RDM } & $15 \mathrm{ds}$ & $1 \mathrm{~A}$ & wPt-9938-wPt-669499 & $51.61-59.35$ & 3.81 & 0.007 & 12.0 \\
\hline & $15 \mathrm{ds}$ & $2 \mathrm{~A}$ & wPt-1772-wPt-743211 & $0.00-15.52$ & 2.28 & 0.005 & 7.5 \\
\hline
\end{tabular}


Table 1 (continued)

\begin{tabular}{llllllll}
\hline Trait & Environment & CHR & Marker interval & cM & LOD & A & R \\
\hline $15 \mathrm{ds}$ & 2B & wPt-1646-wPt-665550 & $79.26-102.63$ & 4.84 & 0.008 & 15.6 \\
$15 \mathrm{ww}$ & 3A & tPt-0519-wPt-7271 & $20.9-27.2$ & 3.81 & -0.09 & 12.1 \\
$15 \mathrm{ds}$ & 3B & wPt-1682-wPt-0571 & $100.53-103.24$ & 2.59 & 0.006 & 8.5 \\
$15 \mathrm{ds}$ & 4B & wPt-5497-tPt-0602 & $21.59-29.11$ & 3.27 & 0.007 & 10.4 \\
$15 \mathrm{ds}$ & 7A & wPt-3403-wPt-7267 & $20.80-39.79$ & 2.77 & 0.006 & 9.2 \\
\hline
\end{tabular}

Traits are defined for $\mathrm{S} 1$. ( $\mathrm{PH}=$ plant height, $\mathrm{HT}=$ heading time, $\mathrm{BM}=$ aboveground biomass, $\mathrm{SW}=$ spike weight, $\mathrm{SL}=$ spike length, $\mathrm{GNE}=$ grain number/main ear, $\mathrm{GY}=$ grain yield, $\mathrm{HI}=$ harvest index, $\mathrm{TGW}=$ thousand grain weight, $\mathrm{RDM}=$ root dry mass), $\mathrm{CHR}$ means chromosome. Marker interval = markers bracketing the 1-LOD support interval. A=average additive effects: positive values indicate an increasing effect of the Plainsman V alleles, and negative values indicate an increasing Cappelle Desprez allele effect. $\mathrm{R}^{2}=$ percent of the phenotypic variation explained. QTL $=$ Quantitative Trait Locus, $\mathrm{LOD}=$ logarithm of odds

number of QTL was detected with the TGW (9), the less with BM (2).

During the experiments 10 agronomic traits were measured. QTL related to HT were identified on chromosome 1B (wPt-6376-wPt-1975), 2B (wPt-5250-wPt744643), 3B (wPt-6376-wPt-9514), 5B (wPt-5250-wPt-0935). The 1B QTL was detected under both conditions in 2016, the 2B QTL was localized in ds conditions in 2015, the 3B and 5B QTL was found in ww conditions (Table 1, Fig. 1). The HT QTL explained the 7.9-23.8\% of the phenotypic variance. On chromosome 1A, 2B, 3B, 4B, 5B, 6B, 7D, PH-related QTL were detected (Table 1, Fig. 1) In addition, two QTL were identified in all years and treatment, which were localized on chromosome 4B (wPt-5334-wPt-5497) and 6B (wPt663764-wPt-2175), the first one explained the 9.7-37.3\% of the phenotypic variance, the other one had smaller effect, 7.3-17\%. QTLs were identified on chromosome 3B under ww conditions and on chromosome $6 \mathrm{~B}$ for ds treatment related to $\mathrm{BM}$.

During the experiments five yield-related traits were measured and in total 30 QTL were identified for them. QTL on chromosome 1A (ds), 1B (ww), 3B (ww, ds), 5B (ww) were detected with SW and they explained from 6.9 to $21.8 \%$ of the phenotyping variance. Another seven QTL was located with SW on chromosome 1A (ww, ds), 2A (ww, ds), 2B (ds), 3B (ww, ds), 5B (ww), 6A (ww), 7A (ww), explaining the $8.5-12.7 \%$ of the phenotyping variance (Table 1). The GNE QTL was located on chromosome 2A (ww), 3B (ww, ds), 6A (ww, ds). In total seven QTL was detected for GY, accounting for 8.6 to $24.0 \%$ of the phenotypic variation. None of them was identified for both conditions. The highest number of QTL among yield-related traits was for TGW with nine QTL. Two of them were identified in both conditions, the QTL on chromosome 6A and 6B were explaining the $7.3-13.9 \%$ of the phenotypic variance. The HI was also calculated in all experiments. Four QTL were identified with this trait, on chromosome 1A, 3B, 6A. None of them was stable in both water regime, they were explaining the $8.5-17.6 \%$ of the phenotyping variance.
The RDM was measured only in one-year 2015 and seven QTL were detected with this trait. The QTL were located on chromosome 1A, 2A, 2B, 3A, 3B, 4B, and 7A (Fig. 1). None of them was identified under both water supply level. The RDM QTL explained from 7.5 to $15.6 \%$ of the phenotypic variance (Table 1).

\section{Discussion}

\section{Phenotypic results, correlation analysis}

The effect of ds on wheat DH lines was evaluated in pot experiments using two different water regimes ( $w w=60 \%$ of the soil water capacity, $\mathrm{ds}=20 \%$ of the soil water capacity) for three years (2014-2016) in glasshouse. The average yield of the DH population was reduced by $50.5 \%, 65.8 \%$, and $70.8 \%$ under ds conditions, respectively, compared to ww conditions in the experiments. Varga et al. (2015) reported similar results in their glasshouse experiment. Czyczylo-Mysza et al. (2018) measured 10-70\% yield loss in their drought tolerance experiment.

Many drought tolerance research focused on GY and its relation to other traits. Medium strength positive correlation was found in the experiments between GY and PH under ds conditions. In agreement with the result Kumar et al. (2018) and El-Feki et al. (2018) reported positive correlation between the two traits. On the other hand, Khan et al. (2005) reported negative correlation. The yield-related traits (GNE, TGW) showed positive correlation with GY under both treatments. These results were like those, Khan et al. (2005); El-Feki et al. (2018); Kumar et al. (2018); Wang et al (2018), who reported strong positive correlation between the traits.

\section{QTL mapping}

\section{QTL distribution}

In total, 54 QTL regions were detected across the three years and two water regimes with 10 traits in the $\mathrm{Pl} /$ 
$1 \mathrm{~A}$

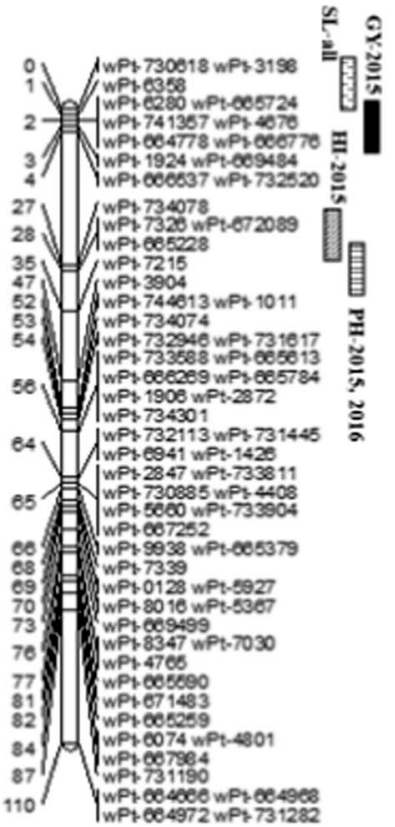

IB

ww QTL
2A

ww QTL

ds QTL
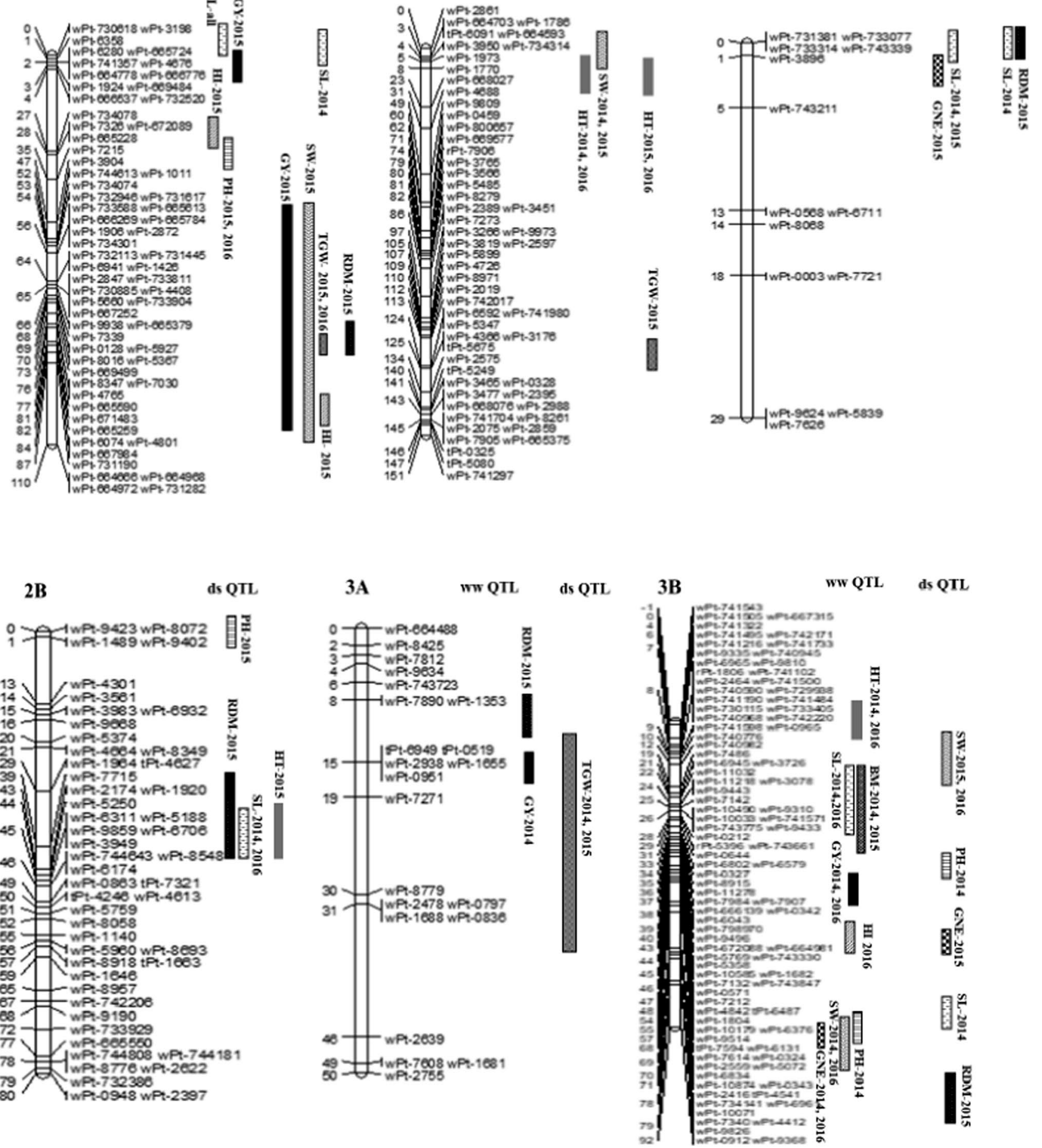

圆兽
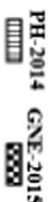

因鱼

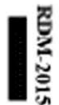

Fig. 1 QTL clusters detected for agronomic traits of the Plainsman V./Cappelle Desprez DH population under two water regimes in three years $(2014,2015,2016)$ under glasshouse conditions

CD DH population. The QTL distribution was balanced between the two water regimes. Twenty-three QTLs were detected only under ds conditions; another 18 QTLs were found only in the ww treatment. Furthermore, 11 QTLs were detected under both conditions. In addition, 2 QTL were detected in all years and water regimes associated with $\mathrm{PH}$ on chromosome 4B, and 6B. The occurrence of QTL was the highest on the B genome (55.5\%). On the A 

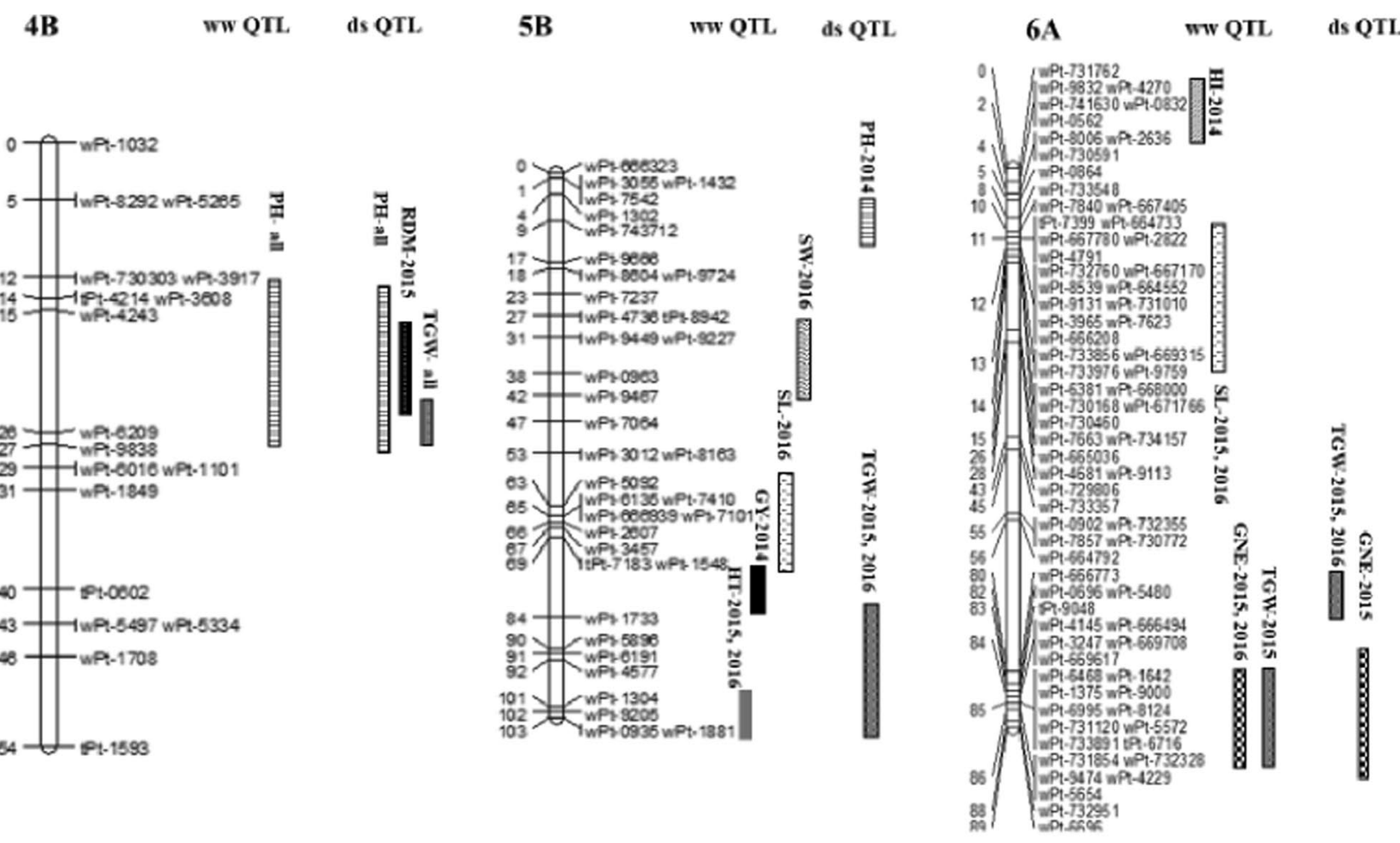

$6 B$ ww QTL ds QTL

$7 \mathrm{~A}$

ww QTL ds QTL

$7 \mathbf{D}$

ds QTL
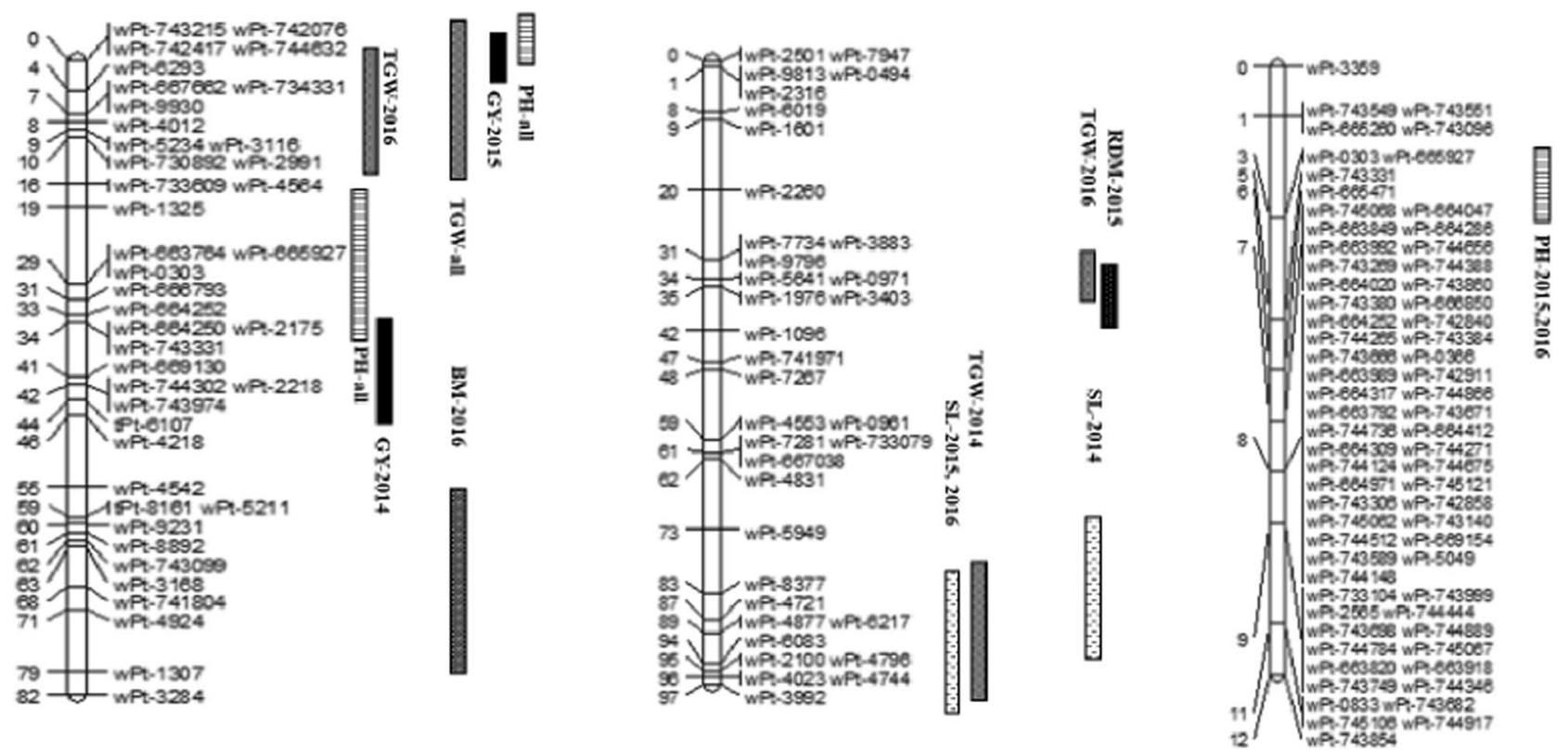

Fig. 1 (continued)

genome 23 QTLs were detected (42.5\%). Only 1 QTL was identified on the D genome (1.8\%). The highest number of QTLs was detected with the TGW (9), the less with BM (2).

\section{Agronomic traits}

Heading time-related QTL was detected on 2D, 7D chromosome (Bogard et al. 2013, S 2.), 2D (Verma et al. 2004). On the contrary, none of those QTLs were localized in our 
glasshouse experiment. The heading time QTL detected on chromosome $3 \mathrm{~B}$ under ww conditions was previously reported by Marza et al. (2006) and Mccartney et al. (2005).

Many QTL were identified related to plant height, on 3B (Bennet et al. 2012a), 6A (Bennet et al. 2012b), 2B, 4B, 5D (Lopes et al. 2013), 4B, 4D (Gao et al. 2015), 2A (Ehdaie et al. 2016). With the Pl/CD DH population under ds conditions six QTL regions were identified, which were located on $2 \mathrm{~B}, 3 \mathrm{~B}, 4 \mathrm{~B}, 5 \mathrm{~B}, 6 \mathrm{~B}$ and $7 \mathrm{D}$ chromosomes. The $\mathrm{PH} \mathrm{QTL}$ on the $2 \mathrm{~B}$ chromosome was reported by Marza et al. (2006), Mathews et al. (2008), Pinto et al. (2010), Thamasebi et al. (2017), El-Feki et al. (2018). The 3B PH QTL was reported by Marza et al. (2006), Shukla et al. (2014). The QTL on 4B chromosome was identified in all our experiments and was reported previously by Cadalen et al. (1998); Huang et al. (2004), Marza et al. (2006).

QTL regions on chromosome 2D and 5D were reported by Osipova et al. (2016) related to BM in drought stress treatment. Shukla et al. (2015) detected QTL on chromosome 3B, 3D, and 3A under drought stress conditions with BM. In addition, Xu et al. (2017) localized QTL region on the 1B chromosome with the same trait. On the other hand, none of the above-mentioned QTL was identified in our experiments. QTL on the 6B chromosome was detected under ds conditions and on $3 \mathrm{~B}$ under $\mathrm{ww}$ conditions and was identified with the Plainsman V/Cappelle Desprez DH population in glasshouse.

\section{Yield, Yield-related traits}

QTL regions related to grain yield and its related traits have been reported previously by numerous authors. Dashti et al. (2007) reported GNE QTL regions on chromosome 1B, 4A, $5 \mathrm{~B}$ in ww treatment and on chromosome 5B, and 7A under ds conditions. GNE-related QTL regions on chromosome 1A (Huang et al. 2004), 3B (Marza et al. 2006; Shukla et al. 2014), and 6B (Huang et al. 2004; Marza et al. 2006; Kuchel et al. 2007) have been identified with the Plainsman V./Cappelle Desprez DH population too.

In the experiments in ww conditions five TGW QTL have been identified (1A, 3B, 4B, 6B, and 7A). The 4B QTL have been previously reported by Nezhad et al. (2012). In addition, Dashti et al. (2007) in ww treatment detected QTL on chromosome $2 \mathrm{~A}, 4 \mathrm{~A}$, and $7 \mathrm{~A}$. In the ds treatment ten TGW QTL regions have been detected with the Plainsman V./Cappelle Desprez DH population. The QTL on chromosome 2B (Kordenaeej et al. 2008; Maccaferri et al. 2008); 3B (Kordenaeej et al. 2008; Pinto et al. 2010; Shukla et al. 2014), 5B (Maccaferri et al. 2008), 6B (Maccaferri et al. 2008), and 7A (2012; Huang et al. 2004) QTLs have been previously reported. The QTL on 1A chromosome, which was identified in both conditions in the experiments, haven't been previously reported.

Yield-related QTL regions were identified on the following chromosomes under drought stress conditions; $1 \mathrm{~A}$ (Bennet et al. 2012b), 1B (Pinto et al. 2010; Lopes et al. 2013), 2D (Hamza et al. 2017; El-Feki et al. 2018), 3A (Hamza et al. 2017), 3D (Kuchel et al. 2007), 4A (Kirgwi et al. 2007; Pinto et al. 2010; Lopes et al. 2013; Shukla et al. 2014; Tahmasebi et al. 2017), 4B (Pinto et al. 2010; Lopes et al. 2013), 4D (Pinto et al. 2010; Lopes et al. 2013), 5A (Hamza et al. 2017; El-Feki et al. 2018), 5B (Kuchel et al. 2007; El-Feki et al. 2018), 5D (Kadam et al. 2012), 6B (Pinto et al. 2010; Lopes et al. 2013), 6D, 7A (Hamza et al. 2017), 7B (Kuchel et al. 2007; El-Feki et al. 2018) 7D (Pinto et al. 2010; Lopes et al. 2013). From the above-mentioned QTL-s the 1A, and 6B QTL were identified under ds conditions in the glasshouse experiments.

HI-related QTL region was identified on chromosome 1A, 3B and 6A with the Plainsman V./Cappelle Desprez DH population under ww conditions. In addition, on chromosome 1A HI-related QTL was identified in ds conditions. Kadam et al. (2012) reported QTL with HI on chromosome $1 \mathrm{~B}, 2 \mathrm{D}, 4 \mathrm{~B}$, and $5 \mathrm{~A}$ in drought treatment. On the other hand, Shukla et al. (2014) identified QTL with this trait under drought conditions on chromosome 2B, 3B, 3D. El-Feki et al. (2018) detected QTL related to HI on chromosome $1 \mathrm{~B}$, and $2 \mathrm{~B}$ under drought conditions and on chromosome $6 \mathrm{~B}$ under both dry and wet conditions.

\section{Root dry biomass}

Zhang et al. (2014) reported QTLs associated with root length on chromosome 5A. Liu et al. (2013) reported that genotypes with the greater root vigor under drought conditions showed the lowest yield reductions under severe water stress and also detected QTL associated with root length on 1A chromosome. Ehdaie et al. (2016) found that root system traits have positive effects on wheat grain yield, particularly in drought conditions. They detected QTL on 2D, and 3A related to total root biomass. Kadam et al. (2012) reported QTL region on chromosomes 2D and 4B with RDM under drought stress. QTLs were identified under ds conditions with the $\mathrm{Pl} / \mathrm{CD} \mathrm{DH}$ population on the $2 \mathrm{~A}, 2 \mathrm{~B}, 3 \mathrm{~B}, 4 \mathrm{~B}$, and 7A chromosomes related to RDM in our experiments. Christopher et al. (2013) reported QTL with RDM in the same position on the $3 \mathrm{~B}$ chromosome.

Supplementary Information The online version contains supplementary material available at https://doi.org/10.1007/s42976-021-00229-y.

Acknowledgements The authors thank the support for scientific projects of Ministry of Innovation and Technology, Ministry of Finance and National Research, Development, and Innovation Office (project numbers: TKP2020-NKA-21, OTKA-K_21-K138416, GINOP 
2.2.1-15-2017-00042, EFOP-3.6.1-16-2016-00016). The authors would like to thank Sándor Vajasdi-Nagy, Ferenc Markó and Szilvia Palaticki for their conscientious work.

Author contributions Éva Nagy carried out the glasshouse experiments and was involved in collection and evaluation of experimental data, QTL data analysis and writing the manuscript. Ágnes Szabó-Hevér was involved in DNA isolation and creating linkage groups. Ágnes Szabó-Hevér, Szabolcs Lehoczki-Krsjak, János Pauk and Csaba Lantos were involved in manuscript preparation. Szabolcs Lehoczki-Krsjak was involved in statistical analysis. Csaba Lantos was involved in production of DH population. Erzsébet Kiss was involved in QTL data analysis supervision. János Pauk was involved in experimental planning and supervision.

Funding Open access funding provided by Cereal Research Non-Profit Ltd.

Open Access This article is licensed under a Creative Commons Attribution 4.0 International License, which permits use, sharing, adaptation, distribution and reproduction in any medium or format, as long as you give appropriate credit to the original author(s) and the source, provide a link to the Creative Commons licence, and indicate if changes were made. The images or other third party material in this article are included in the article's Creative Commons licence, unless indicated otherwise in a credit line to the material. If material is not included in the article's Creative Commons licence and your intended use is not permitted by statutory regulation or exceeds the permitted use, you will need to obtain permission directly from the copyright holder. To view a copy of this licence, visit http://creativecommons.org/licenses/by/4.0/.

\section{References}

Bennet D, Reynolds M, Mullan D, Izanloo A, Kuchel H, Langridge P, Schnurbusch T (2012a) Detection of two major grain yield QTL in bread wheat (Triticum aestivum L.) under heat, drought and high yield potential environments. Theor Appl Genet 125(7):1473-1485

Bennet D, Izanloo A, Reynolds M, Kuchel H, Langridge P, Schnurbusch T (2012b) Genetic dissection of grain yield and physical grain quality in bread wheat (Triticum aestivum L.) under waterlimited environments. Theor Appl Genet 125:255-271

Bogard M, Allard V, Martre P, Heumez E, Snape JW, Orford S, Griffith S, Gaju O, Foulkes J, Le Gouis J (2013) Identifying wheat genomic regions for improving grain protein contrentration independently of grain yield using multiple inter-related populations. Mol Breed 31:587-599

Cadalen T, Sourdille P, Charmet G, Tixier MH, Gay G, Boeuf C, Bernard S, Leroy P, Bernard M (1998) Molecular markers linked to genes affecting plant height in wheat using a doubled-haploid population. Theor Appl Genet 6:933-940

Christopher J, Christopher M, Jennings R, Jones S, Fletcher S, Borrell A, Manschadi AM, Jordan D, Mace E, Hammer G (2013) QTL for root angle and number in a population developed from bread wheats (Triticum aestivum) with contrasting adaptation to waterlimited environments. Theor Appl Genet 126:1563-1574

Collins NC, Tardieu F, Tuberosa R (2008) Quantitative trait loci and crop performance under abiotic stress: where do we stand? Plant Physiol 147:469-486

Cseri A, Sass L, Törjél O, Pauk J, Vass I, Dudits D (2013) Monitoring drought responses of barley genotypes with semi-robotic phenotyping platform and association analysis between recorded traits and allelic variants of some stress genes. Aust J Crop Sci 7:1560-1570

Czyczylo-Mysza IM, Marcinska I, Skrizipek E, Bocianoski J (2018) Genetic analysis of water loss of excised leaves associated with drought tolerance in wheat. Peer J. https://doi.org/10.7717/ peerj-5063

Dashti H, Yazdisamadi B, Bihamata Naghavi MR, Quarrie S (2007) QTL analysis for drought resistance in wheat using doubled haploid lines. Intern J Agr Bio 9:98-101

Donald CM (1962) In search of yield. J Austr Inst Agr Sci 28:171-178

Ehdaie B, Mohammadi SA, Nouraein M (2016) QTLs for root traits at mid-tillering and for root and shoot traits at maturity in RIL population of spring bread wheat grown under well-watered conditions. Euphytica 211:17-38

El-Feki WM, Byrne PE, Reid SD, Halley SD (2018) Mapping quantitative trait loci for agronomic traits in winter wheat under different soil moisture levels. Agronomy 8(133):1-20

Gallé Á, Csiszár J, Secenji M, Guóth A, Cseuz L, Tari I, Györgyey J, Erdei L (2009) Glutathione transferase activity and expression patterns during grain filling in flag leaves of wheat genotypes differing in drought tolerance: Response to water deficit. J Plant Physiol 166:1878-1891

Gao F, Wen W, Liu J, Rasheed A, Yin G, Xia X, Wu X, He Z (2015) Genome-wide linkage mapping of QTL for yield components, plant height and yield-related physiological traits in the Chinese wheat cross Zhou 8425B/Chinese Spring. Front Plant Sci 6:1099

Gao F, Liu J, Yang L, Wu X, Xiao Y, Xia X, He Z (2016) Genomewide linkage mapping of QTL for physiological traits in a Chinese wheat population using the $90 \mathrm{~K}$ SNP array. Euphytica 209:789-804

Guan P, Lu L, Jia L, Kabir MR, Zhang J, Lan T, Zhao Y, Xin M, Hu Z, Yao Y, Ni Z, Sun Q, Peng H (2018) Global QTL analysis identifies genomic regions on chromosomes $4 \mathrm{~A}$ and $4 \mathrm{~B}$ harboring stable loci for yield-related traits across different environments in wheat (Triticum aestivum L.). Front Plant Sci 9:529. https://doi.org/10. 3389/fpls.2018.00529

Hamza H, Asghari A, Mohammadi SA, Sofalian O, Mohammadi S (2017) Multifactorial mapping of QTL for yield and yield component in wheat (Triticum aestivum) in normal and drought conditions. Appl Ecol Environ Res 16(1):441-453

Huang XQ, Kempf H, Ganal MW, Röder MS (2004) Advanced backcross QTL analysis in progenies derived from cross between a German elite winter wheat variety and synthetic wheat (Triticum aestivum L.). Theor Appl Genet 109:933-943

Kadam S, Singh K, Shukla S, Goel S, Vikram P, Pawar V, Gaikwad K, Khanna-Chopra R, Singh N (2012) Genomic association for drought tolerance on the short arm of wheat chromosome 4B. Funct Integr Genom 12:447-464

Khan AJ, Azam F, Ali A, Tarig M, Amin M (2005) Inter-relationship and path coefficient analysis for biometric traits in drought tolerant wheat (Triticum Aestivum L.). Asian J Plant Sci 4(5):540-543

Kilian A, Wenzl P, Huttner P, Carling J, Xia L, Blois H et al (2012) Diversity arrays technology: a generic genome profiling technology on open platforms. Methods in molecular biology. Humana Press, Totowa, pp 67-89

Kirgwi FM, Van Ginkel M, Brown-Guedira G, Gill BS, Paulsen GM, Fritz AK (2007) Markers associated with a QTL for grain yield in wheat under drought. Mol Breeding 20:401-413

Kordenaeej A, Nasrollah-Nejad A, Shojaeian A, Leliey T (2008) Mapping QTLs related to yield and yield components under drought in bread wheat. In: Appels R, Eastwood R, Lagudah E, Langridge P, Lynne MM (edd) The 11th international wheat genetics symposium proceedings. Sydney University Press, Sydney

Kuchel H, Williams KJ, Langridge P, Eagles HA, Jefferies SP (2007) Genetic dissection of grain yield in bread wheat. I QTL Analysis Theor Appl Genet 115:1029-1041 
Kumar S, Kkumari J, Bansal R, Kuri BR, Upadhyay D (2018) Multienvironmental evaluation of wheat genotypes for drought tolerance. Indian Journal of Genetics 78(1):26-35

Lafitte HR, Price AH, Courtois B (2004) Yield response to water deficit in an upland rice mapping population: associations among traits and genetic markers. Theor Appl Genet 109:1237-1246

Li XM, Chen XM, Xiao YG, Xia XC, Wang DS, He ZH, Wang HJ (2014) Identification of QTLs for seedling vigor in winter wheat. Euphytica 198:199-209

Liu X, Li R, Chang X, Jing R (2013) Mapping QTLs for seedling root traits in a doubled haploid wheat population under different water regimes. Euphytica 189:51-66

Lopes SM, Reynolds MP, McIntyre CL, Mathews KL, Kamali MRJ, Mossad M, Feltaous Y, Tahir ISA, Chatrath R, Ogbonnaya F, Baum M (2013) OTL for yield and associated traits in the Seri/ Babax population grown across several environments in Mexico, in the West Asia, North Africa, and South Asia regions. Theor Appl Genet 126:971-984

Maccaferri M, Sanguineti MC, Corneti S, Ortega JL, Salem MB et al (2008) Quantitative trait loci for grain yield and adaptation of durum wheat (Triticum durum Desf) across a wide range of water availability. Genetics 178:489-511

Marza F, Bai GH, Carver BF, Zhou WC (2006) Quantitative trait loci for yield and related traits in the wheat population Ning7840 X Clark. Theor Appl Genet 112:688-698

Mathews KL, Malosetti M, Chapman S, Mcintyre L, Reynolds M, Shorter R, Van Eeuwjik F (2008) Multi-environmental QTL mixed models for drought stress adaptation in wheat. Theor Appl Genet 117:1077-1109

McCartney CA, Somers DJ, Humphreys DG, Lukow O, Ames N, Noll J, Cloutier S, McCallum BD (2005) Mapping quantitative trait loci controlling agronomic traits in spring wheat cross RL4452 X 'AC Domain.' Genome 48:870-883

Nagy É, Lantos C, Pauk J (2017) Selection of drought tolerant and sensitive genotypes from wheat DH population. Acta Physiology Plantarum 39(12):261

Nasseer AM, Martin JM, Heo HY, Blake NK, Sherman JD, Pumphrey M, Kephart KD, Lanning SP, Naruoka Y, Talbert LE (2016) Impact of a Quantitative Trait Locus of tiller numbers on plasticity of agronomic traits in spring wheat. Crop Sci 56:595-602

Nezhad ZK, Weber WE, Röder MS, Sharma S, Lohwasser U, Meyer RC, Saal B, Börner A (2012) QTL analysis for thousand-grain weight under terminal drought stress in bread wheat (Triticum aestivum L.) Euphytica 186:127-138

Osipova S, Permyakov A, Permyakova M, Pshenichnikova T, Verkhoturov V, Rudikovsky A, Rudikovskaya E, Shishparenok A, Doroshkov A, Börner A (2016) Regions of the bread wheat D genome associated with variation in key photosynthesis traits and shoot biomass under both well-watered and water deficit conditions. J Appl Genet 57:151-163

Passioura JB (1983) Roots and drought resistance. Agric Water Manag 7:265-280

Pauk J, Mihály R, Puolimatka M (2003) Protocol for wheat (Triticum aestivum L.) anther culture. In: Kasha K, Maluszynski M (eds) Doubled haploid production in crop plants. Kluwer Academic Publisher, Dordrecht/Boston/London, pp 59-64

Pinto SR, Reynolds MP, Mathews KL, McIntyre CL, Olivares-Villegas JJ, Chapman SC (2010) Heat and drought adaptive QTL in wheat population designed to minimize confounding agronomic effects. Theor Appl Genet 121:1001-1021

Pouri K, Sio-Se Mardeh A, Sohrabi Y, Soltani A (2019) Crop phenotyping for wheat yield and yield components against drought stress. Cereal Res Commun 47(2):383-393

Rampino P, Pataleo S, Gerardi C, Mita G, Perrotta C (2006) Drought stress response in wheat: physiological, molecular analysis of resistant, sensitive genotypes. Plant Cell Environ 26:2143-2152
Rogers SO, Bendich AJ (1985) Extraction of DNA from milligram amounts of fresh, herbarium and mummified plant tissues. Plant Mol Biol 5:69-76

Safar-Noori M, Assaha DVM, Saneoka H (2018) Effect of salicylic acid and potassium application on yield and grain nutritional quality of wheat under drought stress condition. Cereal Res Commun 46(3):558-562

Shukla S, Singh K, Patil RV, Kadam S, Bharti S, Prasad P, Kumar Singh N, Hanna-Chopra R (2015) Genomic regions associated with grain yield under drought stress in wheat (Triticum aestivum L.). Euphytica 203(2):449-467

Sinha N, Priyanka V, Ramya KT, Leena T, Bhat JA, Harikrishna Jain N, Singh PK, Singh GP, Prabhu KV (2018) Assessment of markertrait associations for drought and heat tolerance in bread wheat. Cereal Res Commun 46(4):539-549

Tahmasebi S, Heidari B, Pakniyat H, Mcintyre CL (2017) Mapping QTLs associated with agronomic and physiological traits under terminal drought and heat stress conditions in wheat (Triticum aestivum L.). Genome 60(1):26-45

Tavakol E, Elbadry N, Tondelli A, Cattivelli L, Rossini L (2016) Genetic dissection of heading date and yield under Mediterranean dry climate in barley (Hordeum vulgare L.). Euphytica 212:343-353

Teulat B, Zoumarou-Wallis N, Rotter B, Ben Salem M, Bahri H, This D (2003) QTL for relative water content in field-grown barley and their stability across Mediterranean environments. Theor Appl Genet 108:181-188

Van Ooijen JW (1999) LOD significance thresholds for QTL analysis in experimental populations of diploid species. Heredity 83:613-624

Van Ooijen JW, Voorrips RE (2001) JoinMap Version 3.0: Software for the calculation of genetic linkage maps. Kyazma BV, Plant Research International, Wageningen

Van Ooijen JW (2004) MapQTL Version 5: software for the mapping of quantitative trait loci in experimental populations. Kyazma BV, Plant Research International, Wageningen

Varga B, Vida G, Varga-László E, Bencze S, Veisz O (2015) Effect of simulating drought in various phenophases on the water use efficiency of Winter Wheat. J Agron Crop Sci 201:1-9

Verma V, Foulkes MJ, Worland AJ, Sylvester-Bradley R, Caligari PDS, Snape JW (2004) Mapping quantitative trait loci for flag leaf senescence as a yield determinant in winter wheat under optimal drought-stressed environments. Euphytica 135:255-263

Wang S, Jia S, Sun D, Fan H, Chang X, Jing R (2016) Mapping QTLs for stomatal density and size under drought stress in wheat (Triticum aestivum L.). J Integr Agric 15(9):1955-1967

Wang X, Zhang X, Chen J, Wang X, Cai J, Zhou Q, Dai T, Cao W, Jiang D (2018) Parental Drought-Priming Enhances Tolerance to Post-anthesis Drought in Offspring of Wheat. Front Plant Sci 9:261

Xu YF, Li SS, Li LH, Ma FF, Fu XY, Shi ZL, Xu HX, Ma PT, An DG (2017) QTL mapping for yield and photosynthetic related traits under different water regimes in wheat. Mol Breeding 37:34-42

Zhang B, Liu W, Chang SX, Anyia AO (2010) Water deficit and high temperature affected water use efficiency and arabinoxylan concentration in spring wheat. J Cereal Sci 52:263-269

Zhang J, Hao C, Ren Q, Chang X, Liu G, Jing R (2011) Association mapping of dynamic developmental plant height in common wheat. Planta 234:897-902

Zhang H, Cui F, Wang L, Li J, Ding A, Zhao C, Bao Y, Yang Q, Wang H (2013) Conditional and unconditional QTL mapping of drought-related traits of wheat seedling using two RIL populations. J Genet 92(2):213-231

Zhang H, Cui F, Wang H (2014) Detection of quantitative trait loci (QTLs) for seedling traits and drought tolerance in wheat using three related recombinant inbred line (RIL) populations. Euphytica 196:313-330 